\title{
A ascensão do combustível fóssil: aspectos tecnológicos, sociais, econômicos e ambientais da substituição da lenha pelo carvão mineral
}

\author{
Carlos Augusto Arentz Pereira $^{1}$
}

凹arentz.uerj@gmail.com

Resumo: A lenha como combustivel de maior utilização pela humanidade, foi sendo substituída pelo carvão mineral a partir do século XIII, devido a uma série de fatores. Assim, o carvão mineral se tornou a energia motriz da Segunda Revolução Industrial após a invenção da máquina térmica no século XVIII. 0 texto aborda os diversos aspectos tecnológicos, sociais, econômicos e ambientais que influenciaram neste processo, que culminou pela adoção do combustivel fóssil como energético de maior consumo nos últimos duzentos anos.

Palavras-chave: Energia, Lenha, Carvão, Combustiveis Fósseis, Tecnologia.

\section{The rise of the fossil fuel: technological, social, economic and environmental aspects of the substitution of wood for coal}

\begin{abstract}
Firewood as humankind's most used fuel, was replaced by coal from XIII century on due to a number of factors. Thus coal became Second Industrial Revolution driving energy after the invention of the thermal machine in XVIII century. This text addresses the various technological, social, economic and environmental aspects that influenced this process, which culminated in the adoption of fossil fuel as the most consumed energy in the last two hundred years.
\end{abstract}

Keywords: Energy, Firewood, Coal, Fossil Fuels, Technology.

\section{El ascenso del combustible fósil: aspectos tecnológicos, sociales, económicos y ambientales de la sustitución de la leña por el carbón mineral}

\footnotetext{
Resumen: Leña como combustible de mayor uso por la humanidad, fue siendo sustituida por el carbón mineral a partir del siglo XIII, debido a una serie de factores. Así, el carbón mineral se convirtió en la energía motriz de la Segunda Revolución Industrial después de la invención de la máquina térmica en el siglo XVIII. El texto aborda los diversos aspectos tecnológicos, sociales, económicos y ambientales que influenciaron en este proceso, que culminó con la adopción del combustible fósil como energético de mayor consumo en los últimos doscientos años.
}

Palabras clave: Energía, Leña, Carbón, Combustibles Fósiles, Tecnología. 
A Energia em suas diversas formas tem sido um bem fundamental ao crescimento econômico e é indiscutivelmente um dos pilares da civilização. Mesmo compreendendo que o conceito de energia é difícil de expressar de forma simples (COELHO, 2007), há que entender que se trata, contudo, de um bem acessório, não fundamental a vida, mas que proporciona conforto ou facilidade na execução de tarefas.

A evolução tecnológica aliada à expansão da ocupação do planeta pela raça humana colaborou para um aumento na sofisticação do uso final da energia. Houve aumento na necessidade de transporte com deslocamentos a maiores distâncias de cargas mais pesadas, concomitantemente com a utilização de construções mais altas, cujo próprio soerguimento passou a exigir maior energia. A necessidade de maior aproveitamento do tempo do dia para execução de tarefas passou a requerer iluminação alternativa à luz solar, com uma qualidade de luz mais próxima da luz natural diurna, aumentando a demanda por combustíveis iluminantes. 0 espalhamento da humanidade pela superfície terrestre também passou a implicar condicionamento de ambientes, primeiramente para aquecimento e a posterior para refrigeração. A própria diversificação e refinamento da produção de bens passou a consumir mais energia quer na agricultura, pecuária ou indústria. Pode-se considerar, que antes do invento da máquina térmica ou máquina a vapor, a necessidade de potência era suprida por força animal, hidráulica ou eólica e para as demais demandas, destaca-se por larga margem, o consumo de combustíveis, principalmente os oriundos de biomassa na maior parte da história registrada (SMIL, 1994).

Na Grã-Bretanha, antes do século XIII, lenha era um material fundamental à civilização, utilizado em construção e engenharia, de edificações a embarcações e sendo também o principal combustível para aquecimento e cocção. 0 crescimento da população e da atividade econômica provocaram desmatamento das terras de florestas circunvizinhas às cidades, para sua própria edificação e expansão, além do uso desta terra para cultivo de alimentos. Este processo aumentou a oferta de lenha, incrementando seu uso como energético. Assim, o problema consequente não foi a disponibilidade de suprimento, mas sim o transporte, uma vez que com o abate das florestas próximas, a lenha tinha de vir de regiões mais distantes. As estradas à época eram precárias, à exceção de algumas poucas vias construídas pelos romanos, mas que não haviam sido projetadas para cargas de maior porte. A forma mais eficaz de transporte de lenha para os centros de consumo das grandes cidades, e principalmente 
A ascensão do combustível fóssil: aspectos tecnológicos, sociais, econômicos e ambientais da substituição da lenha pelo carvão mineral

Londres, era através das hidrovias. Aliás, esta era uma das principais formas de abastecimento de produtos de grande massa para a cidade. Neste mesmo período, incentivado pela questão da distância e custo de transporte, afloramentos de carvão mineral próximos começaram a ser explorados e o carvão usado como substituto da lenha. Esta troca somente foi possível porque os equipamentos - fornos, lareiras, aquecedores - em que se queimava lenha também podiam sem qualquer adaptação queimar carvão. Como o carvão fornecia mais energia por massa transportada que a lenha, a similaridade de custo de transporte e a possibilidade de uso de ambos sem necessidade de adaptação, rapidamente promoveu a substituição (HUMPHREY; STANISLAW, 1979).

Antes de 1700, a maioria das minas de carvão era pequena, sendo explorada pela família do dono da terra para consumo próprio, ou atendimento de um mercado local próximo para aquecimento doméstico ou uso na pequena indústria, como fabricação de tijolos, vidro, curtumes e ferraria. Os primeiros sistemas de mineração consistiam na remoção superficial do carvão, que ocorria em afloramentos ou em pedreiras já abertas. Depois que todas estas ocorrências eram exauridas, prosseguia-se cortando o morro lateralmente, acompanhando as eventuais falhas geológicas existentes, mas ainda a céu aberto. Esta forma de mineração não necessariamente propiciava um aumento de produção. Para obter maior extrativismo, passouse à escavação de minas cada vez mais profundas, seguindo os veios mais ricos em carvão. Neste ponto, a extração de minério deixou de ser uma atividade artesanal, executada por um pequeno grupo de pessoas usando pás de madeira, picaretas de pedra e o carvão sendo transportado em sacos no lombo de animais ou nas costas dos homens para fora da mina. A necessidade de aprofundamento das minas e o aumento da demanda, num estágio tecnológico estático, passou a exigir proporcionalmente mais pessoal e investimentos, e neste ponto da cadeia de suprimento ocorreram as maiores transformações.

A primeira é quanto à propriedade do minério. Na Grã-Bretanha do século XIII havia consenso que os afloramentos pertenciam ao proprietário da terra ou aos habitantes da região, mas os veios subterrâneos geraram controvérsias de justiça entre o Rei e os proprietários das terras. A decisão foi favorável aos senhores de terra, que exploravam 0 carvão com seus próprios meios ou concediam o direito de exploração a mineiros especializados, tendo como contrapartida o recebimento de um "royalty" em função da quantidade minerada. A produção obtida era vendida aos mesmos mercadores que transportavam lenha para as cidades, sendo que 0 maior custo do carvão ao consumidor permanecia sendo o do transporte, o que o mantinha competitivo à lenha (FREEMAN, 1980). 
Conclui-se que foram a escassez regional de lenha e o menor custo por quantidade de energia transportada (HUMPHREY; STANISLAW, 1979) que propiciaram a competitividade do carvão mineral frente à lenha. Ambos atendiam ao mesmo consumo final e utilizavam as mesmas estruturas logísticas de suprimento, pelo menos na distribuição final àqueles consumidores, a diferença de custo residia no processo de exploração dos energéticos. A atividade de exploração da lenha era basicamente a mesma em qualquer lugar, o processo de derrubada das árvores. 0 aumento do custo da quantidade ofertada era função da extração ocorrer em áreas cada vez mais distantes dos centros de consumo, e, por conseguinte, com custo de transporte maior. Já o carvão se concentrava num mesmo local, logo com um custo de transporte invariável em relação ao mercado de consumo.

Custos menores aumentaram a competitividade do carvão e seu uso se tornou generalizado em Londres, alarmando os cidadãos quanto a questões de saúde, por se acreditar, com razão, que a fumaça do carvão produziria doenças nos pulmões. Não havia até então chaminés nas casas, porque antes se considerava que os fumos da lenha eram benéficos à saúde. Foi solicitada ao Parlamento a proibição da queima de carvão por ser um incômodo insuportável. Assim em 1280, as Câmaras dos Lordes e Comuns do Parlamento, reunidas representando os cidadãos de Londres, queixaram-se ao Rei Eduardo I, pedindo a proibição do uso de carvão. 0 Rei acatou, emitindo uma proclamação proibindo a queima de carvão em Londres e arredores, ordenando às pessoas que as lareiras para aquecimento utilizassem somente lenha. Os ferreiros eram isentos desta proibição devido às exigências de sua profissão. Este édito foi ignorado, apesar de uma segunda queixa do Parlamento e a nomeação de uma Comissão Real, com ordens de punir todos os infratores com multas, e destruir todos os fornos que queimassem carvão (NEF, 1932). Ao longo de centenas de anos seguintes, protestos, reclamações, éditos reais e leis tentam restringir o uso do carvão. Há registros que damas requintadas da sociedade londrina do século XVII se recusavam a entrar em ambientes aquecidos por carvão ou a ingerir alimentos cozidos com ele. Contudo, as forças de mercado, movidas pelos preços menores, foram mais fortes que as proclamações reais, e o carvão não só continuou a ser usado, como acabou encontrando o seu caminho para o Palácio Real, que passou a utilizar aquecimento a carvão em cerca de 1680 (BANK, 1883). Consequência destes aspectos, em 1650, ainda antes da invenção da máquina a vapor, o consumo de carvão mineral igualou o de lenha e derivados na Grã-Bretanha e 50 anos depois já o superava pelo dobro (FOUQUET; PEARSON, 2003). 0 processo de entrada do carvão mineral, substituindo o consumo de lenha, ocorreu inicialmente de forma marginal, impulsionada pelo custo relativo mais baixo, 
A ascensão do combustível fóssil: aspectos tecnológicos, sociais, econômicos e ambientais da substituição da lenha pelo carvão mineral

apesar de apresentar características menos atraentes do que a lenha no consumo (RHODES, 2007).

No início dos anos de 1700, dois acontecimentos foram determinantes para a disparada da demanda por carvão. Em 1709, Abraham Darby descobriu que carvão mineral calcinado poderia ser utilizado para produzir ferro em substituição ao carvão vegetal e, em 1712, Thomas Newcomen desenvolveu um motor a vapor para bombear água das minas e este foi rapidamente adotado, porque inundação era um problema comum às profundas minas de carvão. Em verdade, o motor de Newcomen era muito ineficiente e levou muito tempo para que o método de Darby pudesse ser amplamente utilizado, mas estas invenções lançaram as bases para a grande expansão da demanda por carvão. Ambas permitiram ampliar a utilização do carvão mineral no espectro de consumo energético, a tecnologia de Darby aumentando a substituição de lenha ou carvão vegetal e a máquina a vapor, permitindo a substituição da tração animal (FOUQUET, 2010). Com o advento da máquina a vapor houve uma explosão de consumo de carvão, fazendo que em 1800, a lenha representasse somente 10\% do consumo de combustível do país (FOUQUET; PEARSON, 2003).

A análise deste histórico permite identificar os aspectos tecnológicos, sociais, econômicos e ambientais que contribuíram para tornar o carvão mineral no energético substituto da lenha, mesmo anteriormente à sua função de energia motriz da Revolução Industrial (HATCHER, 1993). Estes fatores somados aparentam ter colaborado de forma decisiva à perpetuação do mercado do carvão, que praticamente relegou a um segundo plano longínquo a utilização da biomassa como energético de significância no desenvolvimento econômico por alguns séculos. A tal ponto chegou esta substituição que em meados do século XIX, a utilização intensa e indiscriminada do carvão mineral chegou a fazer alguns estudiosos levantarem preocupações sobre uma potencial exaustão das reservas na Grã-Bretanha e o impacto deste evento no progresso da nação (JEVONS, 1866).

A substituição da lenha combustível pelo carvão mineral ocorreu no limiar do invento da máquina térmica, tornando o último, o energético motriz da Revolução Industrial. Estes fatores, somados ao aumento populacional e diversificação do consumo em termos de sofisticação de produção e demanda de potência, provocaram um salto gigantesco em termos de consumo absoluto de energia nos últimos duzentos anos. Enquanto a população mundial cresceu 12 vezes, o consumo de energia aumentou 10 milhões de vezes (SOTIROPOULOS, 1994). Estas etapas foram fundamentais à adoção em larga escala do uso dos combustíveis fósseis pela humanidade. 


\section{REFERÊNCIAS BIBLIOGRÁFICAS}

BANK, M.K. Early coal mining. The Ohio Mining Journal, v. 1, n. 4 p. 158-168. Columbus, OH, August 15, 1883. Disponível em: 〈http://hdl.handle.net/181l/32330〉. Acesso em: 20 abril 2019.

COELHO, R. L. On the concept of energy: how understanding its history can improve physics teaching. Science and Education, [S.l.], v. 19, p. 91-113, 2007. Disponível em: 〈http://link.springer.com/article/10.1007\%2Fsl1191-007-9128-0〉. Acesso em: 18 abril 2019.

FOUQUET, R. Divergences in the long run trends in the price of energy and of energy services. [S.I.]: Basque Centre For Climate Change, $\quad$ Feb. 2010. $\quad$ Disponível em: https://www.bc3research.org/index.php?option=com_wpapersótask=downpubliơiddoc=14\&̊ltemid=279\&lang=en_EN >. Acesso em: 20 abril 2019.

FOUQUET, R.; PEARSON, P. J. G. A thousand years of energy use in the United Kingdom. The Energy Journal, [S.I.], v. 19, no. 4, 1998. Disponível em: 〈http://www.jstor.org/stable/41322802〉. Acesso em: 20 abril 2019.

FREEMAN, M. J. Road transport in the English industrial revolution: an interim reassessment. Journal of Historical Geography, [S.I.], v. 6, no. 1, p. 17-28, 1980. Disponível em: <www.sciencedirect.com/science/article/pii/0305748880900419〉. Acesso em: 20 abril 2019.

HATCHER, J. The history of the British coal industry. 0xford: Clarendon Press, 1993. v. 1.

HUMPHREY, W. S.; STANISLAW, J. Economic growth and energy consumption the UK 1700-1975. Energy Policy, [S.I.], p. 29-42, Mar. 1979. Disponível em: 〈http://www.sciencedirect.com/science/article/pii/030142157990049l〉. Acesso em: 20 abril 2019.

JEVONS, W. S. The coal question: an inquiry concerning the progress of the nation and the probable exhaustion of our coal mines. 2. ed. London: Macmillan, 1866.

NEF, J. U. The rise of the British coal industry. London: Routledge, 1932. v. 2.

RH0DES, R. Energy transitions: a curious history. Stanford, CA: Stanford University, 19 Sept. 2007. Disponível em: $<$ https://fsilive.s3.us-west-l.amazonaws.com/s3fs-public/Rhodes-Energy_Transitions.pdf /. Acesso em: 20 abril 2019.

SMIL, V. Energy in world history. Boulder, C0: Westview, 1994.

SOTIROP0ULOS, V. Global balances. Grécia: Aristotle University of Thessaloniki, 1994. Disponível em: <

https://biopolitics.gr/biowp/wp-content/uploads/2013/04/V0L-V-Sotiropoulos.pdf >. Acesso em: 17 abril 2019. 